\title{
Fighting for the NHS, and research integrity
}

\author{
Fiona Godlee editor, BMJ
}

I'm writing this from the BMA's annual representative meeting in Cardiff. The location seems appropriate. Outside the conference hall is a statue of the NHS's founder Aneurin Bevan. The NHS "will only last as long as there are folk left with the faith to fight for it," he once said. Inside the hall the faithful are fighting. One speaker brandishes her well worn copy of Bevan's book In Place Of Fear. She says she's old enough to remember its publication. "For the first time ever I'm afraid," she says.

The government's plans for the English NHS, detailed in its embattled bill, are "the final step on the road to privatisation," says a founder of Keep Our NHS Public. And attempts to mollify the bill's critics have left us with what Hamish Meldrum, chairman of BMA Council, calls "a dog's dinner." Contributors to our feature concur (doi:10.1136/bmj.d3995). "Vast sums of public money and the energy and commitment of thousands of talented people could be wasted implementing policies with little or no evidence base," says Andy Haines.

So where now? In our editorial Tony Delamothe, Edward Davies, and I say that Mr Lansley's monster should be buried in an unmarked grave (doi:10.1136/bmj.d4050). BMA representatives reach a similar conclusion, voting to call for the bill to be withdrawn. The Cardiff representatives narrowly miss reaching a similarly damning verdict, with just over half of them voting against calling on the BMA to oppose the bill in its entirety (doi:10.1136/bmj.d4126).

The conference began on a different note with a talk from Peter Wilmshurst on dishonesty in medicine. Wilmshurst has been an unshakable thorn in the side of those who would prefer misconduct swept under the carpet. "The problem isn't the few dishonest doctors-every profession has them," he told me afterwards. "It's that everything in the UK is geared to preventing people exposing misconduct: whistleblowers are bullied, defamation laws protect the guilty, doctors tolerate misconduct, and institutions cover it up."

In this week's BMJ, Clare Dyer asks why the UK has failed so miserably to tackle research misconduct (doi:10.1136/bmj. d4017). Inadequacies in the system have been highlighted by the Andrew Wakefield saga. It took years before he was finally sanctioned and his study on MMR vaccine and autism retracted. "The effects of the failure to tackle his wrongdoing more quickly and decisively are still being felt," writes Dyer. His institution failed to properly investigate when serious concerns were raised in 2004. University College London is at last seeking to make good this failure and has told me that its investigation will aim to be thorough, fair, wide ranging, timely, and transparent, and will involve external scrutiny. This sounds promising. We must wait and see.

But the UK still lacks a statutory body with a mandate and forensic skills to investigate allegations and to enforce publication of the outcome. Iain Chalmers and Andy Haines call for such a body to be set up without delay (doi:10.1136/ bmj.d4017). Until we have this, history tells us that institutions will continue to put their reputations above patient and public interests. Distracted though it may be by its problems with the NHS, the UK government must urgently address this shameful lack.

Cite this as: $B M J$ 2011;342:d4129 